\title{
O PROFESSOR CRÍTICO-REFLEXIVO: ALTERNATIVAS PARA A SUPERAÇÃO DA EDUCAÇÃO TECNICISTA
}

Critical-reflective teacher: alternatives to overcome a traditional education

El profesor crítico-reflexivo: alternativas para la superación de la educación tecnicista

Received: october/2020

Accepted: december $/ 2020$

Available online: december/2020

Mário Allan da Silva Lopes, Doutorando em Educação, Universidade do Estado do Pará, Brasil.

E-mail: marioallan19@yahoo.com.br

Thayanne Cristinne Costa de Menezes, Especialista em Psicologia Educacional com Ênfase em Psicopedagogia Preventiva, Universidade Federal do Pará, Brasil. E-mail:

thayannemenezes2012@gmail.com

Resumo: Este artigo objetiva discutir alternativas para superar a visão tecnicista dos professores construída na educação básica, observando também a vivência no seu processo de formação no ensino superior. É uma pesquisa bibliográfica que dialoga com Monteiro (2015), Oliveira (2016), Domingo (2012), entre outros. A democratização da educação é uma busca incessante do professor crítico-reflexivo em suas práticas pedagógicas, que por vezes entra em conflito com a hegemonia político-educacional. Através do diálogo com outros autores, espera-se assim contribuir para a superação de uma educação tecnicista, que exclui, julga e marginaliza, principalmente, os mais desfavorecidos da sociedade brasileira.

Palavras-chave: Ensino, Formação crítica-reflexiva, Educação tecnicista. 


\begin{abstract}
This article aims to discuss alternatives to overcome the teachers' technical vision built in basic education, also noting the experience in their training process in higher education. It is a bibliographic research that dialogues with Monteiro (2015), Oliveira (2016), Domingo (2012), among others. The democratization of education is an incessant quest of the critical-reflective teacher in his pedagogical practices, which sometimes comes into conflict with political-educational hegemony. Through dialogue with other authors, it is hoped to contribute to the overcoming of a technical education that excludes, judges and marginalizes, mainly, the most disadvantaged in Brazilian society.
\end{abstract}

Keywords: Teaching, Critical-reflexive formation, Traditional Education.

Resumen: Este artículo pretende discutir alternativas para superar la visión tecnicista de los profesores construida en la educación básica, observando también la vivencia en su proceso de formación en la enseñanza superior. Es una investigación bibliográfica que dialoga con Monteiro (2015), Oliveira (2016), Domingo (2012), entre otros. La democratización de la educación es una búsqueda incesante del profesor crítico-reflexivo en sus prácticas pedagógicas, que a veces entra en conflicto con la hegemonía político-educativa. A través del diálogo con otros autores, se espera contribuir a la superación de una educación tecnicista, que excluye, juzga y margina, principalmente, a los más desfavorecidos de la sociedad brasileña.

Palabras clave: Enseñanza, Formación crítica-reflexiva, Educación tecnicista.

\title{
INTRODUÇÃO
}

Este trabalho busca a partir das produções científicas disponíveis, como livros e dissertações, discutir alternativas para superar a visão tecnicista dos professores construída na educação básica, não deixando de lado a vivência deste profissional no seu processo de formação no ensino superior.

Julgamos também necessário fazer essa discussão a partir de nossa vivência em um curso que forma professores, o de Licenciatura em Pedagogia da Universidade do Estado do Pará, no ano de 2015, atentando para o processo formativo do curso, apontando para as possibilidades de formar-se um professor diferenciado, crítico e que deveria, ao menos é o que se espera, sair da universidade e pôr em prática tudo o que foi aprendido em 4 anos de curso.

Metodologicamente, esta é uma pesquisa bibliográfica, que de acordo com Severino (2007, p. 122) “[...] é aquela que se realiza a partir do registro disponível, decorrentes de pesquisas anteriores, em documentos impressos, como livros, artigos, teses, etc. Utiliza-se de dados ou de categorias teóricas já trabalhados por outros pesquisadores e devidamente registrados". Assim, foi realizada uma revisão de literatura. 
Alguns conceitos essenciais são trabalhados neste estudo e que constituem a formação dos professores desde muito tempo. A educação sempre esteve marcada por interferências externas a ela, que influenciava diretamente a formação dos professores e consequentemente dos alunos, fato este que até hoje nos faz discutir no âmbito político e social, a quem de fato a educação está servindo.

Um dos conceitos aqui empregados é o da educação tecnicista ou pedagogia tecnicista, que de acordo com Silva (2016, p. 198) "coaduna com a lógica do modelo de competências ao ter como base uma educação que privilegia a lógica da instrução e a transmissão da informação".

Apesar de muito se falar e todos os discursos irem de contra à ela, é a educação que ainda está presente no currículo e nas escolas e que, de certa forma, configura-se como amarras para a maioria dos professores que saem do ensino superior prontos para serem o diferencial nas salas de aula.

Nos moldes da racionalidade técnica, o positivismo de Augusto Comte traria para a educação o pensamento científico como o único capaz de constituir uma sociedade desenvolvida e instruída. Este conhecimento técnico-científico seria difundido através das escolas e marcaria a história educacional e da formação docente profundamente (OLIVEIRA, 2016).

\section{A educação técnico-científica}

Como dito anteriormente, a educação tecnicista assumiu um papel de destaque dentro do currículo educacional e dentro das escolas. Há de se deixar claro que não necessariamente o professor é formado nos moldes tecnicistas, mas as escolas em que ele atuará exigem que ele se torne. De acordo com Oliveira (2016, p. 93):

\footnotetext{
A escola passa a ser o espaço privilegiado de transmissão e difusão do conhecimento científico; a ciência o "sinônimo" de "verdade" e o saber científico adquire uma conotação de "poder" em relação ao saber popular. Os intelectuais modernos (técnicos, especialistas) assumem a função social de produtores/transmissores do saber científico.
}

Diante deste cenário, os saberes não científicos acabam por ficar de fora das escolas básicas e o professor se vê num difícil dilema entre conciliar o que o currículo educacional exige e a formação intelectual e crítica dos seus alunos. Infelizmente muitos professores 
acabam por desistir de ir contra ao sistema imposto e não por sua culpa, mas por não ter seus esforços reconhecidos e considerados essenciais para as autoridades educacionais.

Neste contexto, o aluno torna-se o mais prejudicado, ao enfrentar uma escola que está preocupada unicamente com a formação técnico-científica, preparando para o mercado de trabalho. Neste processo o aluno é quase que um produto, que ao final precisa estar pronto para servir a um sistema econômico e político, ou seja, os alunos precisam ser eficientes e capazes de contribuir para a sociedade, como aponta a citação de Peixoto e Nunes (2016, p.03):

Ocorre uma busca que pretendia superar a incompetência, a ineficiência improdutiva. Por isso, era necessário formar indivíduos eficientes, capazes de contribuir para o aumento da produtividade na sociedade. Na pedagogia tecnicista o enfoque fôra no aprender a fazer, em detrimento da pedagogia tradicional, centrada no aprender e da escolanovista, no aprender a aprender (SAVIANI, 2008 apud PEIXOTO; NUNES, 2016, p. 03).

Há um claro interesse mercadológico na educação e no contexto brasileiro esse interesse se torna muito evidente ao observarmos o total desrespeito que a classe dos professores sofre pela política brasileira. De acordo com Domingo (2012, p. 101) a educação tecnicista basicamente se propõe a resolver problemas de caráter instrumental, ou seja, imediatistas e que se afastam de uma solução socialmente mais profunda:

\footnotetext{
A ideia básica do modelo de racionalidade técnica é que a prática profissional consiste na solução instrumental de problemas mediante a aplicação de um conhecimento teórico e técnico, previamente disponível, que procede da pesquisa científica. É instrumental porque supõe a aplicação de técnicas e procedimentos que se justificam por sua capacidade para conseguir os efeitos ou resultados desejados (DOMINGO, 2012, p. 101).
}

A visão tecnicista da educação também coloca o professor em um papel de diagnosticador de problemas, no qual ele precisa resolver com eficácia. Há uma certa ilusão em achar que o professor precisa tomar certas decisões técnicas e que resolva problemas de forma imediata. Devemos lembrar que o professor na educação básica trabalha com crianças e que não há nada de simplista em trabalhar com seres humanos, muito pelo contrário, é complexo e requer mais do que o puro tecnicismo. Domingo (2012, p. 107) nos traz um exemplo de uma atitude tecnicista na educação:

Ao reconhecer o problema diante do qual se encontra, ao ter claramente definidos os resultados que deve alcançar, ou quando tiver decidido qual é a dificuldade de aprendizagem de tal aluno ou grupo, selecionar entre o repertório disponível o tratamento que melhor se adapta à situação e o aplica. 
No entanto, muito se discute acerca das práticas dos professores e já há um movimento dentro dos cursos de licenciaturas, principalmente os vinculados aos programas de Educação, que procuram desmantelar essa velha concepção tecnicista para que assim os professores possam chegar nas salas de aula sabendo lidar com as cobranças curriculares, mas não deixando de incluir no processo educacional temas mais abertos e subjetivos, como bem aponta Domingo (2012, p. 117):

O que o modelo de racionalidade técnica como concepção da atuação profissional revela é sua incapacidade para resolver e tratar tudo o que, é imprevisível, tudo o que não pode ser interpretado como um processo de decisão e atuação regulado segundo um sistema de raciocínio infalível, a partir de um conjunto de premissas.

\section{As dificuldades do ser professor}

A profissão docente está inteiramente ligada à qualidade e a respeitabilidade com que as autoridades educacionais empregam para este profissional, desde a sua formação, manutenção em sala de aula até a sua formação continuada. Para Domingo (2012, p. 105) "no campo da educação, a falta da aplicação técnica de grande parte do conhecimento pedagógico, juntamente com a natureza ambígua e, por vezes, conflituosa de seus fins, levou a que se considere o ensino como uma profissão somente em um sentido muito fraco e limitado".

Esse entendimento da profissão docente como uma profissão fraca e limitada proporciona aos professores os mais variados problemas que acabam por interferir em seu desempenho. De acordo com Monteiro (2015) são vários os fatores que podem contribuir para dificultar de alguma forma a vida do profissional docente em sala de aula, que podem ainda influenciar na sua vida pessoal. Monteiro (2015) aponta alguns desses fatores, como o “estatuto profissional e social pouco prestigiado" (MONTEIRO, 2015, p. 130):

A profissão de professor no Brasil não é valorizada como deveria, o que lhe acomete inúmeras críticas e concepções errôneas fazendo, inclusive, com que muitos jovens no ensino superior as escolham como a "segunda opção" para cursarem. De acordo com Monteiro (2015, p. 130) a profissão docente “ é geralmente vista como sendo uma profissão de acesso fácil”, lhe trazendo pouco prestígio perante a sociedade. Além disso Monteiro (2015, p. 131) também afirma não ser uma profissão bem paga comparada a outras formações acadêmicas análogas, além de "a sua autonomia [ser] limitada pela sua dimensão política e coletiva".

Outro fator é o das "condições de trabalho deficientes ou degradadas" (MONTEIRO, 2015, p. 131). Monteiro (2015) aponta que o ritmo acelerado do ano letivo, principalmente 
tendo que cumprir cargas horárias e muitas matérias para trabalhar atrapalham o percurso do professor no processo ensino-aprendizagem. Aliado a isso, a enorme quantidade de alunos para um único professor em sala, com poucos recursos tecnológicos e estruturais, alimenta mais essas dificuldades. Outro fator que o autor aponta é a sobrecarga de tarefas, o que é bem interessante para ser refletido, visto que em muitas escolas de educação básica o professor desempenha papéis que de nada tem a ver com o seu processo formativo.

O autor também nos apresenta "outros aspectos de uma imagem desvalorizante" (MONTEIRO, 2015, p. 131-2): a desvalorização acaba não vindo só das autoridades políticas, mas, de certa forma, até da sociedade. De acordo com Monteiro (2015, p.132) a profíssão docente “ é, talvez, a profissão mais exposta à opinião pública, visibilidade que a torna mais escrutinável e potencia a repercussão pública da mediocridade e abusos dos piores profissionais". Além disso, o autor ainda traz outros fatores como o encontro com alunos agressivos em sala de aula (agressividade que por vezes parte também das mães e dos pais).

As dificuldades encontradas pelos professores em sala de aula, como podemos observar, não são só de ordem epistemológica e política, mas também de cunho social e isso interfere diretamente na sua atuação profissional e vida pessoal, culminando com a desvalorização da profissão não só aos olhos “dos outros”, mas também do próprio professor, passando a não enxergar uma melhora em seu percurso.

Essas dificuldades podem influenciar na formação do professor crítico-reflexivo, dificultando cada vez mais a possibilidade desse profissional se sentir livre para desempenhar suas funções de forma mais criativa, crítica, reflexiva, didática, e com isso fazendo com que este professor opte pelo mecanicismo encontrado na educação tecnicista.

\section{A formação do professor crítico-reflexivo nas escolas brasileiras}

A formação crítica-reflexiva do professor começa, epistemologicamente, dentro dos cursos de licenciaturas. Um curso de ensino superior deve ser crítico e reflexivo em sua essência, falando principalmente das universidades e faculdades públicas. As discussões nas disciplinas dos cursos precisam permear um linha muito tênue, onde de um lado temos o cientificismo empregado no currículo dos cursos e do outro lado uma epistemologia humanizadora, socialmente e culturalmente construída, que possa levar seus alunos a pensarem criticamente o modelo educacional posto no Brasil. Segundo Domingo (2012, p. 118): 
A ideia de profissional reflexivo desenvolvida por Schön $(1983$; 1992) trata justamente de dar conta da forma pela qual os profissionais enfrentam aquelas situações que não se resolver por meio de repertórios técnicos; aquelas atividades que, como o ensino, se caracterizam por atuar sobre situações que são incertas, instáveis, singulares e nas quais há conflitos de valor.

Em muitos casos das universidades públicas brasileiras, há um grande trabalho e estudos de grandes autores clássicos da educação, que nos contribuem para essa formação crítica-reflexiva e que ajudam a pensar uma práxis mais eficiente para a formação humanizada dos nossos alunos. Autores como Paulo Freire, Carlos R. Brandão, Boaventura de S. Santos, entre outros, discutem uma educação e uma epistemologia que vai de contra a hegemonização científica empregada durante os anos pelo pensamento tecnicista no Brasil.

Há uma certa "visão moral" que a escola inspira, de acordo com Monteiro (2015), e essas discussões já começam a acontecer dentro dos cursos de ensino superior, contribuindo com a formação do professor crítico-reflexivo. Em muitos casos, já acontecem inclusive nas salas de aula do ensino básico, visto que muitos professores conseguem entre uma aula obrigatória e outra, incluir discussões sociais, políticas e culturais em suas aulas.

Monteiro (2015) apresenta uma um relatório do ano de 2012 intitulado Refondons I'École de la République ${ }^{l}$, resultado de uma pesquisa nacional sobre a escola, realizada na França. Nos relatórios são listadas algumas recomendações do que a escola inspiradora deveria adotar e julgamos necessário trazer alguns desses pontos, pois dialoga com muita maestria com o que aqui estamos discutindo.

$\mathrm{O}$ autor começa nos colocando que "a escola deve abandonar a sua 'postura enciclopédica'. Hoje, tão importante como aprender é 'aprender a aprender'” (MONTEIRO, 2015, p. 267): essa recomendação é muito sucinta e aponta um grande problema que ainda constatamos nas escolas brasileiras, uma "educação enciclopédica", que na grande maioria das vezes está totalmente desvinculada da realidade dos alunos e do Brasil de modo geral. No entanto, já conseguimos visualizar em algumas escolas e em alguns professores a iniciativa de tentar trazer um pouco da realidade que cerca os alunos, para dentro da sala de aula.

Monteiro (2015, p. 267) afirma que "a escola é um lugar de instrução, de formação intelectual e de transmissão de valores, tanto como de preparação para a vida social e profissional": aqui queremos dar destaque para a "preparação para a vida social". Ora, de que forma se prepara uma criança para a vida social? Não apenas com conteúdos escolares, mas

\footnotetext{
${ }^{1}$ Proposta de reformular a escola pública.
} 
permitindo-a conhecer o mundo em que ela vive em todos os seus sentidos, contribuindo para a sua reflexão e crítica acerca da sociedade em que ela vive. O autor continua dizendo que é necessário superar a "oposição estéril entre instrução e educação", que são as "duas pernas" do sistema educativo, que deve também "transmitir uma ampla cultura, humanistas, científica e artística" (MONTEIRO, 2015, p. 267), chegando assim num ponto crucial para uma nova educação, longe do puro tecnicismo curricular. Uma educação cultural prevê uma formação ampla que vai além de mero conteudismo, pois engaja o aluno num processo formativo onde vários contextos estão empregados. Falar de cultura é falar de respeito ao outro, a nós mesmo e a tudo que nos cerca.

O autor aponta também que "é necessário repensar as modalidades de avaliação, para que não sejam fatores de diminuição do sentimento de valor pessoal e de desmotivação" (MONTEIRO, 2015, p. 268): uma proposta de avaliação que permitisse avaliar continuamente a evolução do aluno, de forma qualitativa e menos quantitativa, serial o ideal. As avaliações através das notas não são capazes de mostrar a real situação do aprendizado do aluno enquanto um ser crítico e reflexivo, limitando-o a meros números em um boletim escolar. Talvez atividades que envolvessem rodas de conversas, debates, produções literárias, dentre outras, fossem bem mais eficientes neste novo modo de avaliar qualitativamente, ou melhor, não "avaliar", mas acompanhar as construções críticas e reflexivas que o aluno é capaz de realizar.

Em outro ponto, Monteiro (2015, p. 268) discorre que "a escola não é apenas um lugar de aprendizagens, mas também um lugar de vida. Deve estar, pois, atenta à qualidade do acolhimento". Deve ser arquitetonicamente, ergonomicamente e humanamente acolhedora para os estudantes, suas famílias e professoras e professores: um ponto que já é autoexplicativo. A escola é um lugar de vida, logo deve preocupar-se com a vida das pessoas que fazem parte deste lugar. Essa preocupação não é só externa, com estruturas e recursos, mas essencialmente interna, preocupando-se com a boa qualidade e respeito para com os professores e alunos e todos os profissionais que atuam na escola.

Diante disso, podemos entender que ser um professor crítico-reflexivo, ou seja, pensar e refletir de forma crítica não é agir fora dos ideias educacionais que estão postos, mas através deles “[...] 'definir-se' diante dos problemas e atuar consequentemente, considerando-os como situações que estão além de nossas próprias intenções e atuações pessoais" (DOMINGO, 2012, p. 179). 
E são muitos os problemas encontrados tanto na educação quanto fora dela, na sociedade em geral. São problemas de âmbito político, sociais, culturais, que envolvem desrespeito, preconceito, falta de sensibilidade, enfim, falta de uma educação mais humanizada.

Por fim, será que nós, professores, estamos realmente preparados para atuar como professores crítico-reflexivos nas salas de aula? Estendo esse questionamento para além das salas de aula da escola básica, incluindo também o ensino superior. São muitas as discussões acerca do assunto, mas ainda bem poucas as ações, principalmente quando temos um programa de ensino que nos força, nos prende e dificulta a possibilidade de humanizar cada vez mais a educação.

Algumas pesquisas têm apontado uma série de problemas que nos provam o quanto a educação ainda precisa caminhar bastante para alcançarmos essa humanização. Nem sempre são problemas realmente propositais, mas são frutos de uma dinâmica social construída durante anos, que passaram por gerações e que se enraizaram em nossa sociedade. E esses problemas podem ser os pontos iniciais para que futuros (e até atuais) professores possam começar a refletir e criticar a sua profissão e o seu modo de atuar.

\section{Por uma educação humanizadora}

Para começarmos essa discussão, queremos esclarecer que compreendemos que ser um professor crítico-reflexivo é o primeiro passo para alcançarmos uma educação mais humanizadora. Vemos que os problemas na educação são históricos e que só tendem a piorar com o passar dos tempos. Conforme aponta Souza (2002, p. 37):

Quando olhamos as relações na educação, do ensino fundamental ao ensino superior, observamos quão desgastadas estão baseadas quase que somente no ensino de conteúdos, os quais se encontram, muitas vezes, calcados em conteúdos fatuais, sem nenhum significado ou sentido para alunos e professores.

Souza (2002, p. 39) faz um interessante questionamento em seu artigo "Relações interpessoais e universidade: desafios e perspectivas", quando se pergunta: "Qual a função da psicologia da educação no curso de Pedagogia?". Ela tenta desvencilhar-se da concepção puramente científica da disciplina e compreende que trabalhar com seres humanos requer conhecê-los, "[...] como pensam, como agem e por que o fazem de determinadas formas" (SOUZA, 2002, p. 39). A autora se coloca como uma eterna aprendiz, não somente dos 
métodos e dos ensinamentos, mas também de si mesma: conhecer-se a si mesmo para assim poder conhecer o outro.

Essa dinâmica do conhecer a si e ao outro revela um movimento social e de construção de sociedade no qual o tecnicismo não dá conta e por isso ele exclui. Este processo é marcado por conflitos, mas que por vezes não é discutido ou então passa totalmente despercebido dentro das salas de aula. Estes conflitos são frutos de toda interatividade que ocorre entre professor e aluno e como afirmam Tardif e Lessard (2013, p. 235) "ensinar é um trabalho interativo".

Diante disso, corroboramos com o que aponta Freire (1987, p. 79) ao dizer que "ninguém educa ninguém, como tampouco ninguém se educa a si mesmo: os homens se educam em comunhão, mediatizados pelo mundo". Este trabalho em comunhão é necessário para se alcançar a educação em sua forma mais plena: aquela que liberta das amarras do preconceito, do ódio, do racismo, da guerra e de muitas outras mazelas sociais.

A educação tem esse papel de transformar o ser humano, de transformar a sociedade, mas para isso, ela precisa do empenho ativo do ser humano, como nos coloca Freire (2000, p. 31): "se a educação sozinha não pode transformar a sociedade, tampouco sem ela a sociedade muda."

Esse trabalho interativo ou em comunhão, pressupõe a construção de uma certa relação entre professores e alunos e que permite o afloramento de possíveis discussões dentro da sala de aula. Logo, traremos alguns pontos que permeiam a sociedade e que estão cada vez mais sendo discutidos em todos os âmbitos, ficando mais difíceis de não serem retratados no contexto educacional.

\section{Podemos falar de preconceito em sala?}

Um primeiro ponto bem interessante e que vem ganhando forma dentro da academia tanto em eventos (seminários, palestras, rodas de conversas) quanto na forma de produção científica (teses, dissertações, artigos) são os que discutem sobre os preconceitos. Cada vez mais evidente na sociedade e consequentemente dentro do contexto educacional, o preconceito nas suas mais variadas formas ganham uma atenção de destaque para que o futuro professor crítico-reflexivo trabalhe e constitua, junto com seus alunos, uma formação cidadã, humanizada e ética para sua vida profissional, mas também social, como nos coloca Mendonça (2018, p. 36): 
[...] oportunizar que a formação inicial contribua para que os futuros professores detenham condições de problematizar a sua profissão e atuar de modo reflexivo e crítico, exercendo assim seu papel social. Digo isso, por entender e acreditar que uma das principais finalidades da formação inicial é responder às demandas sociais e auxiliar na edificação de uma sociedade humanista baseada em princípios como igualdade e equidade.

Mendonça (2018) em sua pesquisa de mestrado em educação, ao entrevistar alunos de licenciatura, percebe que o tema preconceito é muito forte dentro da vida acadêmica. Ao deparar-se com a fala de um dos seus sujeitos, no qual ela nomeia "Renato Russo", o aluno deixa bem claro que a vida na universidade contribuiu para que ele entendesse melhor todos os preconceitos de orientação sexual que ele havia passado, principalmente quando teve a oportunidade de ler trabalhos acerca do tema. Nas palavras do próprio "Renato Russo":

[...] Então, eu consegui lidar muito melhor com essas questões durante o percurso acadêmico e não sofri, não foi algo que me fez sofrer no espaço. Então foi muito melhor, a minha vivência aqui, em relação a esses assuntos, em relação a essa questão do preconceito. Foi muito mais enriquecedor, até porque eu comecei a ter um pouco mais de percepções e um pouco mais de leituras sobre o assunto, então eu já lidei muito melhor com relação a isso na universidade. (Renato Russo) (MENDONÇA, 2018, p. 122).

Mas ainda assim temas como estes não alcançam, em termos acadêmicos, uma discussão profunda e que levasse à reflexão tanto de professores quanto de alunos. Na própria universidade isso ainda é visto muito como temas "a parte" das discussões dentro do currículo e na sala de aula. Sim, como já mencionei, há muitos eventos e trabalhos que tratam deste assunto, mas ainda estão sendo engendrados pelos alunos e centros acadêmicos, ou seja, quase nada partindo das universidades.

Agora imaginemos, se na universidade a discussão não é desenvolvida, o que dirá das escolas públicas do ensino básico. Portanto, consideramos que esse debate é uma das alternativas essenciais para a construção de professor crítico-reflexivo, tanto do professor em sala de aula quanto de seus alunos, que serão futuros profissionais. No ensino básico, as crianças que estão cercadas por todo o tipo de influência social, devem sim fazer parte destacada de uma discussão que cada vez mais está chegando na vida delas, seja na família, pelas mídias eletrônicas, pela escola ou pela comunidade que a cerca.

\section{Podemos falar de política na sala de aula?}


Este item que parece um tanto óbvio, na realidade não tem a ver, diretamente, com o fato de um professor ser defensor de um modelo político para governar o país. Aqui falamos da política enquanto uma ação que permita o aluno refletir e criticar sobre o mundo em que ele vive, que fuja da banalidade educacional que tanto cerca as nossas escolas públicas. Podemos entender que,

\begin{abstract}
A escola pública, cada vez mais, está sendo controlada por políticas autoritárias, anti dialógicas, encobertas por projetos Políticos Pedagógicos que se dizem democráticos, no entanto, escondem ora discursos (neo)liberais, ora discursos de base social-democrata. Com a massificação do ensino público, o baixo investimento por parte do Estado e total descaso dos governos, somado ao esvaziamento dos currículos, a escola pública tornou-se uma célula social cada vez mais hermética. A escola pública perdeu-se em si mesma, desvinculada da realidade das comunidades a que atende, mostra-se como um aparelho de reprodução da ideologia da classe burguesa (LEITE, 2010, p. 2).
\end{abstract}

A educação tecnicista, historicamente, adquiriu um papel de dominação hierárquica, onde quem sabe mais, assume posições privilegiadas na sociedade. Isso é reflexo de uma sociedade preocupada com a aquisição de poder e que encontrou na educação e, consequentemente, nas suas práticas pedagógicas, uma maneira de se estabilizar e manter uma determinada desigualdade social. É muito comum observarmos comerciais de governos, que estão construindo escolas, revitalizando outras; no entanto, na prática, a própria mídia televisiva e também alunos e professores (através de protestos e por meio das redes sociais) mostram uma realidade totalmente diferente daquela apresentada pelos governos.

Diante de tal quadro em que se encontra a educação, onde vemos que a política influencia muito mais a educação, do que o contrário, devemos compreender que o fazer pedagógico em sala de aula também precisa preocupar-se com o estado político do ser. Leite (2010, p. 3) afirma que

Os interesses políticos e as práticas pedagógicas, historicamente, mantêm uma relação que visa a dominação. Embora essas relações sejam desiguais, pois a política influencia muito mais a educação do que vice-versa, não podemos negar a importância do fazer pedagógico no seu estado político.

E é neste contexto que Freire (1987) defendeu uma educação libertadora, que permitisse o aluno encontrar em si mesmo e no outro, seus colegas, seus professores, uma possibilidade de ser protagonista e de protagonizar a própria construção do conhecimento. Ora, isso é ser político, isso representa um fazer pedagógico político, é uma afronta à proposta 
tecnicista de educação, é tornar o silenciado e o marginalizado, pensadores e críticos da própria ciência.

\section{As práticas do professor crítico-reflexivo e a democratização da educação}

Outro ponto que trazemos para discussão é a prática do professor crítico-reflexivo. Essa prática, que por vezes recebe críticas e influências de vários organismos da sociedade, refletem o que Libâneo (2018) diz ser os objetivos da educação. Para o autor, esses objetivos são divididos da seguinte forma:

a) Pelo sistema escolar, que expressa as finalidades educativas de acordo com ideais e valores dominantes na sociedade;

b) Pela escola, que estabelece princípios e diretrizes de orientação do trabalho escolar com base num plano pedagógico-didático que represente o consenso do corpo docente em relação à filosofia da educação e à prática escolar;

c) Pelo professor, que concretiza no ensino da matéria a sua própria visão de educação e de sociedade (LIBÂNEO, 2018, p. 135).

Queremos destacar aqui o primeiro e o terceiro objetivos. Veja que o primeiro objetivo é expressado através do sistema escolar, este normalmente vinculado a uma concepção política e econômica de governo que consequentemente interferirá nas práticas educacionais, interessados em formar profissionais para assim servir o seu modelo político. Esta concepção acaba entrando em conflito com os ideais de um professor crítico-reflexivo, que tenta através das suas críticas sociais, incorporar na educação algumas reivindicações que nascem no seio das camadas populares e dos menos desfavorecidos, tornando a educação mais democrática possível. Sobre isso, Libâneo (2018, p. 136) aponta:

\footnotetext{
Na sociedade de classes, como é a brasileira, os objetivos da educação nacional nem sempre vão expressar os interesses majoritários da população, mas, certamente, podem incorporar aspirações e expectativas decorrentes das reivindicações populares. É preciso que o professor forme uma atitude crítica em relação a esses objetivos, de forma a identificar os que convergem para a efetiva democratização escolar e os que a cerceiam.
}

Libâneo (2018) nos chama a atenção, enquanto profissionais da educação, para a necessidade de os professores assumirem uma posição de críticos do modelo educacional vigente, e com isso serem críticos das práticas pedagógicas, do dever da escola, dos conhecimentos considerados dominantes, etc. Essas práticas contribuirão para a formação crítica-reflexiva não só do professor, como também de seus alunos. 
Essas práticas pedagógicas podem levar a democratização ou não, da educação. Devemos ter o entendimento que essa democratização não partirá apenas do professor em sala de aula, mas também de um movimento curricular, onde todos os agentes educacionais estejam alinhados, na busca por práticas acolhedoras.

\section{Considerações finais}

Trabalhar o tema "professor crítico-reflexivo" nos permite pensar em nós mesmos, sobre nossas práticas, sobre nossos anseios e preocupações com a educação. Refletir sobre si mesmo é a forma mais difícil de criticar, mas também nos permite evoluir e procurar o melhor no nosso profissionalismo.

Não foi intenção deste trabalho criar uma espécie de cartilha ou um manual de como o professor deve agir em sala de aula, mas sim contribuir com um debate que há tempos vem sendo realizado no âmbito epistemológico, mas que ainda encontra dificuldades em alcançar pleitos maiores, dada a falta de sensibilização de um modelo político educacional tecnicista que ainda vigora em muitas escolares brasileiras.

Portanto, ao apresentar temas importantes como o preconceito, a política e a democratização da educação, debates que cercam o âmbito educacional, mas que ainda causam muitas discussões e embates tanto dentro do meio educacional quanto fora, na sociedade de modo geral, tentamos apontar que estes debates podem começar cada vez mais a ganhar força por parte do professor dentro de sala de aula. A luta não pode ser somente dos alunos e muito menos fora da sala, precisa começar lá, debatendo cientificamente, com respaldo e responsabilidade. Preparar os alunos para o que encontrará fora do ambiente acadêmico.

O trabalho precisa continuar, há muito o que ainda se discutir e pôr em prática, mesmo com as dificuldades é possível visualizar o esforço dos professores nas escolas brasileiras e que têm, cada vez mais, problematizado muitos temas que circulam em nossa sociedade e que por vezes são mascarados ou ainda silenciados.

Por fim, gostaríamos de exaltar os professores que no seu dia a dia em sala de aula, tentam a partir de suas próprias concepções, possibilidades e recursos, democratizar a educação, contribuindo para a formação de cidadãos e seres humanos sensibilizados, reflexivos e críticos, em uma sociedade que ainda impera o egoísmo, o individualismo e a coerção na educação. 


\section{REFERÊNCIAS}

DOMINGO, J. C. Autonomia de professores. Trad. Sandra Trabuco Valenzuela. São Paulo: Cortez, 2002.

FREIRE, P. Pedagogia do oprimido. 17. ed. Rio de Janeiro: Paz e Terra, 1987.

FREIRE, P. Pedagogia da Indignação: Cartas pedagógicas e outros escritos. São Paulo: Unesp, 2000.

LEITE, R. C. Educação e política: a relação entre o político e o pedagógico. Revista Eletrônica da Faculdade Metodista Granbery, n. 8, jan/jun 2010, pp. 1 - 8. Disponível em: http://re.granbery.edu.br/artigos/MzU3.pdf. Acesso em: 10 abr. 2020.

LIBÂNEO, J. C. Didática. 2. ed. São Paulo: Cortez, 2018.

MENDONÇA, T. S. Entre outras mil, és tu... Futuro professor: percepções de estudantes de licenciatura sobre igualdade e preconceito. 2018. 196 f. Dissertação (Mestrado em Educação) - Programa de Pós-Graduação em Educação, Universidade do Estado do Pará. Pará, 2018.

MONTEIRO, A. R. Profissão docente: profissionalidade e autorregulação. São Paulo: Cortez, 2015.

OLIVEIRA, I. A. Epistemologia e educação: bases conceituais e racionalidades científicas e históricas. Petrópolis: Vozes, 2016.

PEIXOTO, E. S.; NUNES, L. F. Reflexões sobre a educação tecnicista no Brasil: análise crítica do passado para pensar o presente. In: III Congresso Nacional De Educação, Natal, RN, Brasil, 2016, pp. 1-10. Disponível em: https://editorarealize.com.br/artigo/visualizar/22137. Acesso em: 10 abr. 2020.

SEVERINO, A. J. Metodologia do trabalho científico. 23. ed. rev. e atual. São Paulo: Cortez, 2007.

SILVA, A. V. M. A pedagogia tecnicista e a organização do sistema de ensino brasileiro. In: Revista HISTEDBR On-line, Campinas, $\mathrm{n}^{\circ}$ 70, p.197-209, dez. 2016. Disponível em: https://periodicos.sbu.unicamp.br/ojs/index.php/histedbr/article/view/8644737/15765. Acesso em: 04 dez. 2020. 
SOUZA, V. L. T. Relações interpessoais e universidade: desafios e perspectivas. In: ALMEIDA, L. R.; PLACCO, V. M. N. S. (org.). As relações interpessoais na formação de professores. São Paulo: Loyola, 2002. pp. 35-50.

TARDIF, M.; LESSARD, C. O trabalho docente: elementos para uma teoria da docência como profissão de interações humanas. Trad. João Batista Kreuch. 8. ed. Petrópolis: Vozes, 2013. 